\title{
Classificação de Cargos - Um Estudo de Seus Usos
}

\author{
Monroe F. Day e Glenn D. Thompson \\ tradução de Mary Cardoso
}

Monroe F. Day é chefe-adjunto do Setor de Classificação, da Divisão de Reclamações, tendo antes sido encarregado das atividades de classificação, no Gabinete do Secretário de Estado para - Departamento do Interior, em Chicago, que servia a três divisões descentralizadas.

Glenn D. Thompson é diretor da Seção de Pessoal, da Divisão de Reclamações. Ocupou altos cargos de pessoal em organizações como a Administração do Petróleo na Guerra, o Conselho Federal de Estabilização de Emprêgo e a Administração Federal de Emergência das Obras Públicas.

A

TÉ que ponto são admitidos e aplicados pelos administradores de pessoal, na execução de várias fases de suas atividades específicas, alguns dos usos ou recursos oferecidos pela classificação de cargos? Justificam-se, nas condições que ora prevalecem, as afirmações feitas quanto a êsses usos, em administração de pessoal?

Tais perguntas foram as razões determinantes de um inquérito feito entre funcionários de departamento e de divisão, em cinco das maiores repartições sediadas em Washington, o Departamento do Interior, o do Comércio, o da Marinha, a Administração de Veteranos e o Departamento de Agricultura.

Todos os usos aqui mencionados como tendo sido investigados e registrados foram, nessa ou naquela circunstância, tanto afirmados como questionados. Não faremos citação das fontes porque isso resultaria num artigo enorme, mas indicaremos outro trabalho, como referência informativa. (1) Aliás, nem todos os

(1) "Estudo do Sistema Federal de Classificação de Cargos como um Instrumento da Administração - Usos e Forma de Operação", de Monror F. DAY, págs. 63-88, publ. da Biblioteca da Universidade Americana, 1952. 
usos que se afirma ter a classificação de cargos para a administração de pessoal foram testados pelo presente estudo. Para que assim fôsse, teríamos que aumentar muito o número de itens a serem investigados e, sendo assim, correriamos o risco de ver afetadas a qualidade e a quantidade dos dados utilizados como amostra. Não obstante, o inquérito considerou, de modo geral, os usos da classificação de cargos em conexão com as provas, a chamada de candidatos, e os processos de transferência, enquadramento, promoção, mensuração da eficiência e treinamento. Não teve relação alguma com a técnica da classificação de cargos pròpriamente dita, isto é, referente ao estabelecimento de graus ou niveis, nem com a administração do plano de remuneração, dois tópicos inteiramente distintos. (2)

A bibliografia disponivel sôbre os usos da classificação de cargos é, ainda, substancialmente a mesma indicada em 1943 pelo diretor adjunto de pessoal de uma Comissão Estadual de Serviço Civil, valendo esta observação para salientar que a literatura existente sôbre classificação pràticamente não indica os usos que poderiam ter, nos diferentes órgãos de serviço, as especificações de cargos. E embora o órgão de pessoal seja via de regra encarado como um "setor de staff", sem dúvida tal afirmação lhe é, em essência, noutro sentido, inteiramente aplicável.

O "Questionário para funcionários de pessoal, relativo ao sistema de classificação de cargos e suas relações com certas fases da administração de pessoal" consistia em dez itens e foi distribuido aos funcionários a que já fizemos referência. A parte mais importante dêsse inquérito de dez itens, incluindo os fatos, opiniões e condições descritos pelos que dêle participaram, consta a seguir. Solicitamos respostas anônimas, de modo a permitir o máximo possivel de liberdade de expressão.

\section{COMO FONTES DE INFORMAÇÃO}

a) na preparação de provas

O sistema de classificação de cargos constitui fonte de infor. mações que pode ser usada pela Comissão do Serviço Civil, pelos órgãos examinadores das repartições e por outros serviços de emprêgo, relativamente a fatos concernentes a deveres, responsabilidades e qualificações requeridos no desempenho do trabalho

(2) Para uma análise administrativa da eficácia técnica do sistema de classificação de cargos, veja-se o estudo de MONROE F. DAY, "Os adminis. tradores de linha avaliam a classificação de cargos - Estudo com caráter me:o de novembro de 1952, págs. 16-22, 29. 
atribuído aos cargos. Entretanto, os técnicos de pessoal tiram partido dessa fonte de informações e sabem utilizá-la?

Houve concordância unânime de opiniões no sentido de que os fatos fornecidos pelo sistema de classificação eram aproveitados, em maior ou menor grau, como base para ulteriores estudos ligados à preparação dos testes, mais de dois terços afirmando que freqüentemente a obtenção de tais dados era feita dessa maneira.

b) na avaliação de qualificações básicas

Cêrca de $85 \%$ dos questionados afirmou que os fatos relativos a deveres, responsabilidades e qualificações provinham de fontes oriundas da classificação de cargos, servindo para o esclarecimento dos futuros candidatos, a propósito da avaliação das qualificações fundamentais para o exercício do cargo. $8 \%$ não opinaram, declarando "Não sei". Um pouco mais de $60 \%$ assinalava que o uso de tal fonte de informação era feito com muita freqüência, ao passo que uns $30 \%$ disseram que tal freqüência era baixa. $8 \%$ afirmaram que a informação era sempre usada para êsse efeito, mas por outro lado houve a mesma percentagem de afirmação em contrário.

c) na preparação das listas de candidatos

Uma parcela de mais ou menos $70 \%$ afirmou, em proporções variáveis, que os fatos obtidos através do sistema de classificação eram utilizados como base para ulteriores estudos tendentes à preparação de listas de candidatos, sendo de assinalar-se que um pouco mais de $60 \%$ foi de opin ão que isso ocorria com pouca freqüência, uma pequena percentagem declarando "Sòmente em casos de certificação de seleção". Minoria de pouco mais de $30 \%$ opinou por uma alta taxa de freqüência e uns $8 \%$ responderam "Não sei". A alta percentagem acusando pequena freqüência deve-se muito, sem dúvida, ao fato de que tal função é exercida, especialmente, pela Comissão de Serviço Civil e não pelos Departamentos e Divisões.

d) para contrôle do uso das listas de candidatos qualificados

Um grupo de mais de $3 / 4$ assinalou a circunstância de que os dados obtidos mediante o sistema de classificação eram usados para controlar o uso das listas de candidatos, no atendimento das requisições de pessoal qualificado. Um pouco mais de $60 \%$ afirmou que isso ocorria com grande freqüência, cêrca de $30 \%$ respondeu que a freqüência era pequena e o restante declarou não ter conhecimento suficiente para afirmar num sentido ou no outro. 


\section{NA DIVULGAÇÃO DOS CONCURSOS}

O mais importante documento técnico sôbre classificação de cargos no serviço público registrou situação em que os padrões de classificação foram reproduzidos nas notícias divulgatórias dos concursos, com o objetivo de salientar os dados significativos referentes aos mesmos, tais como, os títulos dos cargos, o trabalho respectivo e as qualificações de ordem geral exigidas.

No inquérito, cêrca de $2 / 5$ dos técnicos de pessoal declarou ter conhecimento de exemplos verificados no govêrno federal, no decorrer dos dez anos anteriores, nos quais os padrões da classificação de cargos haviam sido assim utilizados. Um pouco menos de $1 / 4$ do total de inquiridos afirmou ser frequïente êsse uso e uns setenta por cento responderam que o mesmo ocorria com pouca freqüência. Percentagem ligeiramente maior que a metade do grupo declarou não saber da ocorrência de tais casos, em que os padrões houvessem sido incluídos literalmente nas notícias sôbre os concursos, sendo de assinalar, entretanto, que $8 \%$ dessas respostas indicaram uma tomada de posição, já que foi nelas afirmado "Não quanto a cargos especializados".

\section{NA CONVOCAÇÃO DE CANDIDATOS QUALIFICADOS}

Nos setores que tratam dos problemas de emprêgo e enquadramento (incluindo o exemplo as funções de chamada, certificação e nomeação), ouve-se dizer, às vêzes, que os dados sôbre deveres e qualificações, constantes dos formulários de chamada, são freqüentemente insignificantes e pouco definidos e assim não podem ser de muita utilidade. E' o caso de se procurar então saber se a culpa é dos técnicos de pessoal, que não usam convenientemente as informações contidas nas especificações de cargos ou se os dados são, de fato, em si mesmos deficientes. Tais especificações, bem como a indicação de qualificações especiais de pedidos de certificação, sempre que partio particular na solução pública a existência de especificac̃o que não tenha sido tornada pelas quais seja possivel identifỗes-padrões da classe de cargos, foco.

Ligeira margem acima de $90 \%$ assinalou que os dados sôbre deveres e os requisitos exigidos eram obtidos, com maior ou menor freqüência, de fontes ligadas à classificação de cargos, sendo porém de se notar que pouco menos de $50 \%$ do grupo mencionou uma baixa de freqüência, respoudendo "raramente" ou
"nunca". Notou-se ligeira predominância da opinião favorável a
uma elevada taxa de freqüência apenas da descrição do trabalho". 


\section{NA ECONOMIA DE TEMPO NOS CONCURSOS}

a) identificação de devęres

Um dos melhores argumentos para justificar uma norma, técnica ou instrumento, consiste em indicar economia de tempo, trabalho ou material. Um dos resultados do sistema de classificação é o de permitir a determinação dos deveres que irão caber ao ocupante do cargo. A pergunta, portanto, foi: "O técnico de seleção pode aceitar êsse dado como válido, assim economizando tempo, já que não precisará, em cada nova oportunidade, pesquisar e estabelecer os deveres em tôrno dos quais deverá girar a seleção, sempre que novos empregados devam preencher funções antigas?"

$\mathrm{Na}$ resposta a esta indagação, cêrca de $85 \%$ declarou que, em tais circunstâncias, havia de fato economia de tempo. Percentagem ligeiramente acima de $50 \%$ afirmou que semelhante uso dos resultados da classificação ocorria com muita freqüência, enquanto um pouco menos de $50 \%$ dos questionados assinalou que o mesmo acontecia com pequena freqüência.

b) classes de cargos versus cargos isolados

Todos os técnicos de pessoal declararam reconhecer que o plano de classificação de cargos pode ser usado para economia de tempo, desde que o selecionador esteja interessado, em estabelecer exames-padrões para classes de cargos, de preferência a fazê-lo para cargos isolados, havendo uns $70 \%$ declarado que êsse uso se faz em grande escala.

c) redução do número de listas de candidatos qualificados

O fato de que os deveres não precisam estar sendo repetidamente determinados sempre que se tratar de submeter novos empregados a seleção, para o preenchimento de funções já bem conhecidas, e a circunstância de que o selecionador pode estabelecer provas-padrões para classes de cargos contribuem para reduzir o número de listas de elementos qualificados, que são preparadas para atender às necessidades dos Departamentos. Cêrca de $85 \%$ dos inquiridos afirmou isto e não houve nenhuma declaração direta em contrário. Uns $46 \%$ opinaram quanto à baixa freqüência dêsse fato, ao passo que $39 \%$ disseram que tal freqüência erà alta.

\section{NA SIMPLIFICAÇÃO DAS TRANSFERÊNCIAS}

a) relação dos cargos entre si

Oitenta e cinco por cento das respostas indicaram que o sistema de classificação fornece informações sôbre as relações dos 
cargos entre si, quanto ao tipo e nivel de trabalho, dados êsses que podem ser úteis nos casos de transferência. Mais ou menos $70 \%$ declarou haver usado com freqüência tais informações para efeito de transferências.

b) áreas de atividade

Uma esmagadora maioria superior a $90 \%$ afirmou que o sistema de classificação fornece informações quanto às áreas de atividade onde encontrar pessoal para as transferências e cêrca de $70 \%$ declarou que o uso de tais informações é m;uito freqüente.

c) identificação de rotas profissionais

Ainda aqui mais de $90 \%$ respondeu que, em maior ou menor grau, a classificação de cargos oferece dados que permitem a identificação de rotas profissionais, capazes de boa utilização nos casos de transferência. E' até certo ponto significativo, porém, que mais da metade do grupo investigado declarou que essa fonte de informações é usada com pequena freqüência. Convém, no interêsse de melhor administração e da segurança de mais elevado moral entre os funcionários, que se dê mais atenção a essa área
da administração de pessoal.

\section{NA CORREÇÃO DOS,ÊRROS DE ENQUADRAMENTO}

Para $80 \%$ dos técnicos de pessoal interrogados, o plano de classificação ajuda, em maior ou menor escala. na correlação entre funcionários desajustados e os cargos para que estariam os mesmos mais bem qualificados. Não obstante, apenas uma pequena maioria salientou a utilização do plano, com alta freqüiência, para êsse propósito. Há, portanto, fortes indicios de que os usos da classificação de cargos, no processo de enquadramento de pessoal, não estão sendo feitos em tôda a extensão possivel.

\section{NA DIVULGAÇÃO DE MAPAS DE CARREIRAS, COMO INCENTIVO AO PESSOAL}

Apenas 15\% dos questionados assinalou ter conhecimento de que mapas ou gráficos de organização, em têrmos de cargos de carreira, haviam sido afixados em setores estratégicos do Serviço Federal, com o objetivo de estimular os funcionários com vistas a um plano de promoções. Todos êles responderam que sabiam da ocorrência dêsse fato, "mas raramente", e mais de $90 \%$, considerado todo o grupo sujeito à investigação, acentuou que tal uso da classificação de cargos ocorria com pequena freqüência. 
NA DETERMINAÇÃO DE PADRÕES DE EFICIÊNCIA

O sistema de classificação de cargos oferece informação básica quanto ao trabalho das funções a desempenhar, mas até que ponto tais informes são de fato utilizados no estabelecimento e na administração de planos que visem aos padrões de eficiência?

Aproximadamente $85 \%$ das respostas indicou, em grau maior ou menor, que os dados sôbre o trabalho a executar, apurados no processo de classificação de cargos, eram utilizados para aquêles propósitos, $62 \%$ mencionando uma alta taxa de freqüência nessa utilização e o restante assinalando pequena freqüência para o mesmo fato. Uns poucos, nesse segundo grupo, afirmaram ainda ser de opinião que conviria talvez aproveitar mais amiúde os referidos dados, com vistas ao relativamente recente plano de mensuração de eficiência pôsto em prática pelo Govêrno Federal.

\section{INCLUSÃO DE EXIGÊNCIAS MÍNIMAS DE EXECUÇÃO COMO PARTE DAS ESPECIFICAÇÕES DE CARGOS}

São várias as opiniões freqüentemente manifestadas quanto à conveniência de se incluirem nas especificações de cargos exigências minimas de execução ou eficiência. Assim, considerando que os técnicos de pessoal submetidos ao inquérito seriam certamente afetados por qualquer decisão de caráter compulsório nessa matéria, solicitou-se aos mesmos que expressassem seus pontosde-vista, à luz da experiência de cada um.

Não houve uma determinada opinião que pudesse ser tomada como bem representativa da maioria, mas tão-sòmente uma faixa preponderante de $30 \%$, que declarou que os formulários de classificação deveriam conter sempre uma parte mencionando as exigências minimas de execução. Cêrca de um quarto entendia que a matéria deveria ficar na alçada dos supervisores, enquanto um grupo muito pequeno opinou no sentido de que tal assunto nunca deveria constar das especificações de cargos.

\section{NO DESENVOLVIMENTO DE PROGRAMAS DE TREINAMENTO}

Perguntou-se se os padrões da classificação de cargos são empregados como auxiliares subsidiários pelos técnicos de treinamento, ao elaborarem seus programas. Como resultado apurou-se que $92 \%$ dos inquiridos afirmaram o bom uso dos padrões para efeitos de treinamento, quase todos assinalando que êsse uso era freqüente e uns poucos declarando que tal freqüência era pequena. 


\section{COMENTÁRIOS ESCRITOOS}

Os comentários de ordem geral mais interessantes, feitos pelos técnicos de pessoal interrogados foram os seguintes:

1. "Largamente usado para dirimir conflitos de jurisdição".

2. "Os usos da classificação de cargos acima indicados são prejudicados e obscurecidos pela corrupção do sistema, decorrente de crises em tôrno da fixação de niveis".

3. "Há necessidade de estreita coordenação entre classificadores, técnicos de enquadramento e selecionadores, para que se atinjam os melhores resultados num programa de administração de pessoal. Cada um dêsses grupos precisa ter a perspectiva exata de seu lugar na organização e da relação entre seu trabalho e o dos outros, de modo que cada um possa agir como auxiliar da boa administração e não tentar obter como resultado final apenas seus programas individuais".

4. "Completas e freqüentes inspeções fazem -se necessárias, para assegurar a quantidade e a qualidade do trabalho".

\section{PROGNÓSTICOS} ções:

Tendo em vista o futuro, parecem cabiveis várias observa-

1. Não basta apenas que a administração saiba que a classificação de cargos é um bom auxiliar de quase todos os aspectos da administração de pessoal. Também deveriam ser conhecidos alguns pormenores, como métodos, normas, tipos de conhecimento disponivel ou exigivel, oportunidade no tempo e outros tópicos; que inostram como funciona a classificação de cargos.

2. O conhecimento dêsse instrumento auxiliar não deveria ficar confinado às esferas de pessoal, mas deveria ser extensivo aos setores de linha, orçamento, organização e métodos de trabalho, bem como a outros campos da administração.

3. Nem sempre é bastante também saber que certo tipo de informação é útil até certo ponto. $\mathrm{O}$ grau ou a freqüência com que se pode usar determinado instrumento pode dar, igualmente, a medida exata de sua validade. Se a classificação deve ter sua justificativa em têrmos do uso que dela se faz, então a freqüência dêsse uso, a extensão em que é aplicada e o conteúdo intrínseco da contribuição que presta deveriam ser firmemente esta-
belecidos.

De um modo geral. os indices que êste estudo revela, no tocante a freqüência e validade, são mais positivos que negativos. 
E' necessário, ainda, que haja maior colaboração no órgão de pessoal, tanto no Govêrno como na indústria particular, entre os vários técnicos ocupados em atividades diferentes, como treinamento, classificação, mercado de emprêgo, etc., de modo que possam ser executados, nesses campos, mais realisticos programas. O grau de colaboração que seja mantido determinará, em larga escala, o progresso efetivo, realizado em cada setor.

(In "Personnel Administration (Administração de Pessoal"), vol. 16, $\mathrm{n}^{2}$ 4, Julho. 1953). 